\section{Nature of human sexuality}

SIR - Nessa Carey (Nature 354, 9; 1991) is right to say that homosexuals have been given a bad time by sections of the Church and the medical profession. AIDS is a terrible disease, but it would be foolish indeed not to take advantage of the perhaps unique opportunity it has presented to probe into the interaction between a virus and the immune system. This has resulted in an explosion of interest and research in the scientific community. Among the topics brought into focus is the nature of human sexuality itself. Discussions appear in the press and media that would have been unthinkable only a few years ago.

Human sexuality has always fascinated mankind, as is evident by the many 'Venuses' and phallic objects that have been found from the Stone Age onwards. Plato in his Symposium describes three sexes, males, females and androgynes, each split in half by an angry Zeus, and each forever seeking its partner - a neat way to explain heterosexual and homosexual attraction. There has been no shortage of theories since, but it was Kinsey ${ }^{1}$ who in his famous 0-to-6 scale described humanity not as sheep or goats but with some 50 per cent of humanity at the heterosexual end $(0,1)$ of the scale, 5 per cent at the exclusively homosexual end $(5,6)$ and the rest in between.

More elaborate and useful descriptions have since been propounded ${ }^{2}$ which further differentiate between biological sex, sexual identity, sexual behaviour and preferred sexual outlets and so on, and how these change with time. Some have argued that homosexuality as a fixed entity across culture and time does not exist, but that homosexuality itself is merely a social construct ${ }^{3}$, while other believe in a homosexual 'essence' and cite common factors in the lifestyles and behaviour of homosexuals across culture as evidence ${ }^{4}$.

Dawkins ${ }^{5}$, has suggested that even if there are homosexual genes in modern man, in earlier times, say in our Pleistocene ancestors, these may have interacted with other genes and environments to produce completely different phenotypic characteristics and behaviour, which may have had nothing to do with homosexuality. This is perhaps why efforts to understand the role of genes and intrauterine hormones in the determination of sexual variation in man have proved so unrewarding.

Understanding the role of the hypothalamus, and indeed the brain as a whole, in the construction of gender identity and sexuality is of fundamental importance, and Simon LeVay's work may just offer a key to the process. A luddite approach will help nobody. A biological basis for homosexuality would suggest that it is a part of normal human sexuality, and should no longer be regarded as a mental illness or as an aberration.

R. E. GoOdMan

Psychosexual Clinic, Lancastrian Unit, Hope Hospital, Salford M6 8HD, UK

1. Kinsey, A. C., Pomeroy, W. B. \& Martin, C. E. Sexual Behavior in the Human Male (Saunders, Philadelphia 1948 .

2. Coleman, E. J. Homosex. 14, 9-24 (1987)

3. Weeks, J. Sexuality and its Discontents (Routledge. London, 1985)

4. Whitham, F L Archs sex Behav, 12, 207-226, (1983)

5. Dawkins, R., The Extended Phenotype (Oxford University Press, Oxford, (1982)

\section{Consistent policy?}

SIR - Commercialization of biological sequence data is certainly worrisome and we were pleased to see the attention given to the subject in Nature $\mathbf{3 5 4}, \mathbf{1 7 1}$; 1991). For many years the nucleotide sequence databases have been encouraging authors to submit their data to the appropriate database and working with journals to ensure that authors transfer data. Most molecular biology journals now require that sequence data reported in a publication be deposited in the relevant database. Nature is the exception. It was, therefore, something of a surprise to read that Nature is now strongly in favour of sequence deposition in databases.

On the one hand, the leading article states: "Both MRC and NIH are thus looking for speculative (but probably insubstantial) benefits from the first flush of data with a new technique. The policies are discreditable because they make a monkey of honest research, and because so little thought has been given to the damage they will do. What, for example, will happen to exhortations of those in the academic sector with novel sequence data that they should add them to the public databanks? The case for doing so is strong, for these are eminently databanks in which the whole is greater than the sum of the parts."

On the other hand, Nature as a scientific journal does not think the matter serious enough to warrant more than a mere request to authors: "Nature requests authors to deposit sequence and crystallographic data in the databases that exist for that purpose, and to mention the availability of these data." (Guide to authors, same issue).

One of the main reasons that progress has been so rapid in molecular biology is the free and rapid exchange of data and materials (clones and so on). It is in nobody's interest - not even industry's - to see this cease. Nature and other journals can play an important role by insisting that all data be deposited in machine-readable form in the public databases. Similarly, granting agencies can make it clear that grants are awarded on the understanding that data will be deposited.

Peter R. Sibbalo

LENNART PHILIPSON

GRAHAM CAMERON

European Molecular Biology Laboratory, Postfach 10.2209.

W-6900 Heidelberg, Germany

- There is no inconsistency. Nature shares the general view that the databases are invaluable. One of the many reasons why it does not require that data should be deposited in them is that their managers have given too little thought to their commercial use. It is a pity that the authors of this letter have not dealt with that issue, now even more topical. - Editor, Nature.

\section{Burt files reopened}

SIR - Although it is much to the credit of the British Psychological Society (BPS) to be reconsidering its public discrediting in 1980 of the late Sir Cyril Burt (see Nature 354, 517; 1991), since it has itself been very much parti pris on the question, the BPS cannot now be expected to conduct a truly impartial inquiry into whether it was wrong in what it did ten years and more ago.

As I suggested in an article in the Oxford Magazine (No. 70) last May (my efforts over the previous year to raise the matter in more widely circulated publications having been frustrated!), this would better be done by the British Academy, of which Burt had been a highly respected fellow. The charges of fabrication of data and scientific fraud, first made shortly after his death in 1971, were, however, so serious that they would almost certainly have resulted in his expulsion if they had been substantiated during his lifetime. The British Academy should therefore still have a proper interest in determining whether the charges were indeed well founded.

It is not a question of Burt's rather unfashionable hereditarian views on intelligence and educability being correct, let alone politically correct, but whether he arrived at them dishonestly, by fraud and fabrication. The British Academy has plenty of fellows well able to judge of this, which requires no expertise in educational psychology (better not, in fact, for an unprejudiced point of view), and a small group of them could be asked to examine the evidence and to report as to whether a serious injustice has been done to the posthumous reputation of someone who was once one of their more distinguished fellows.

Gonville and Caius College,

C. B. GOODHART

Cambridge, CB2 1TA, UK 